\title{
FAKTOR-FAKTOR YANG BERHUBUNGAN DENGAN PERILAKU HIDUP BERSIH DAN SEHAT (PHBS) DI DESA KUALU KECAMATAN TAMBANG KAMPAR
}

\author{
Putri Wulandini S, Roni Saputra, \\ Keperawatan, Universitas Abdurrab, Pekanbaru \\ E-mail: putri.wulandini@univrab.ac.id
}

\begin{abstract}
Clean and Healthy Behavior/ PHBS is all health behavior that is done on the basis of awareness so that family members can help themselves in the health field. Health is a treasure that is priceless and to get health is willing to spend excessive funds. Based on the profile of Dinas Kesehatan Provinsi Riau the percentage of PHBS at home is 49,5\%. Nevertheless, the implementation of PHBS in Rural areas remains a highlight and an ongoing program for the Government and District Health Offices. The purpose of this study was to find out "Factors Associated With Healthy Behavior Clean and Healthy (Phbs) In Village Kualu Kampar Sub-District ". The type of quantitative research with correlation design, with a population of 350 heads of households, and a sample of 100 people, the sampling technique is Probability Sampling. Data collection using questionnaire. Data analysis was done univariat and bivariate. The result of the research on the knowledge of the respondents about PHBS in the household is good, that is $64 \%$ of the education of the majority respondent of middle level (SMA) 59\%, the role of health workers in PHBS is less the role that is 54\%, the role of public figure is good that is $56 \%$ PHBS is $51 \%$. Bivariate results obtained pvalue 0.01 educational factors and 0.006 knowledge factor, which means there is a relationship. While the role factor Nakes $p$ value 0.81 and the role of Toma 0.151 , which means no relationship. From this research, it is expected that the participation of health personnel to provide complete information through the extension to the community about PHBS in Household.
\end{abstract}

Keywords: Knowledge, Education, PHBS

\section{PENDAHULUAN}

Kesehatan adalah hak azazi manusia dan sekaligus investasi untuk keberhasilan pembangunan bangsa. Untuk pembangunan kesehatan diarahkan untuk mencapai Indonesia Sehat, yaitu suatu keadaan dimana setiap orang hidup dalam lingkungan yang sehat, berprilaku hidup bersih dan sehat, mempunyai akses terhadap pelayanan kesehatan serta memiliki derajat kesehatan yang setinggitingginya (Dinkes, 2010).

Salah satu misi pembangunan kesehatan di Indonesia adalah menggerakkan dan memberdayakan masyarakat untuk berprilaku hidup bersih dan sehat (PHBS). PHBS dapat diterjemahkan sebagai sekumpulan prilaku yang diparktekkan atas dasar kesadaran dari hasil pembelajaran, yang menjadikan seseorang ataukeluarga dapat menolong diri sendiri dan kesehatan dan mampu berperan aktif dalamk mewujudkan kesehatan masyarakat. Untuk melihat keberhasilan dalam pembudayaan PHBS diukur dengan pencapaian indicator rumah tangga sehat (Pratama, 2010).

PHBS adalah sekumpulan perilaku yang dipraktekkan atas dasar kesadaran atas hasil pembelajaran yang menjadikan seseorang atau keluarga dapat menolong dirinya sendiri dibidang kesehatan dan berperan aktif dalam mewujudkan kesehatan masyarakat. Pembinaan PHBS dilakukan melalui pendekatan tatanan yaitu : PHBS di rumah tangga, PHBS di sekolah, PHBS di tempat kerja, PHBS di institusi kesehatan dan PHBS ditempat umum (Dinkes, 2010).

PHBS di rumah tanggga adalah, upaya untuk memberdayakan anggota rumah tangga agar tahu, mau dan mampu melaksanakan perilaku hidup bersih dan sehat, serta berperan aktif dalam gerakan kesehatan masyarakat. 
Indikator pada tatanan rumah tangga adalah sebagai berikut : 1) Pertolongan persalinan oleh tenaga kesehatan, 2) ASI Eklusif, 3) Konsumsi gizi seimbangan, 4) Penimbangan nBalita minimal 8x setahun, 5) menggunakan air bersih untuk keperluan sehari-hari, 6) Menggunakan jamban sehat, 7) Membuang sampah pada tempatnya, 8) Kepadatan hunian minimal 9 meter per-orang, 9) Lantai rumah kedap air, 10) Melakukan aktivitas fisik / olahraga, 11) Tidak merokok, 12) Mencuci tangan sebelum dan sesudah makan, 13) Menggosok gigi minimal 2x sehari, 14) Tidak minum-minuman keras dan mengkonsumsi narkoba, 15) menjadi peserta Jaminan Pemeliharaan Kesehatan (JPK), 16) Pemberantasan sarang nyamuk minimal seminggu sekali (Media PHBS, 2011)

Perilaku hidup bersih dan sehat adalah dasar dari pencegahan penyakit. Kepala keluarga dan anggota keluarga sering mengabaikan kebiasaan mencuci tangan dengan sabun, memberantas jentik nyamuk, kebiasaan merokok dalam rumah. Dengan demikian pengetahuan kepala keluarga yang rendah akan mempengaruhi anggota keluarga dalam memperoleh dan mencerna informasi untuk kemudian menentukan pilihan dalam menerapkan hidup sehat (Hasni, 2012)

Banyak masalah kesehatan yang timbul akibat PHBS tidak dilakukan dengan baik dalam tatanan rumah tangga, seperti terjadinya penyakit diare pada bayi dan balita yang mendapatkan pertolongan yang terlambat akibat keluarga tidak peka dengan kondisi bayi dan balitanya. Adanya mitos bahwa diare adalah berhubungan dengan proses perkembangan anak :"tambah kepandaian", sehingga membiarkan anak dirumah tanpa segera mencari pertolongan ke tenaga kesehatan. Masih banyaknya kejadian Demam berdarah (DBD) yang disebabkan oleh gigitan nyamuk aedes aegypti dan kurang memperhatikan kebersihan lingkkungan (adanya air tergenang, baju bergelantungan, prilaku kepala keluarga yang merokok dalam rumah sangat mempengaruhi kesehatan ibu hamil, bayi dan balita (anonym, 2010). Adanya bayi balita yang tidak melakukan kunjungan posyandu, gizi buruk pada balita jug merupakan akibat kurangnya kesadaran masyarakat akan pentingnya PHBS dalam tatanan rumah tangga (novita, 2014). PHBS menuntut kesadaran setiap anggota keluarga untuk dapat menolong dirinya sendiri dalam bidang kesehatan.

Banyak factor yang mempengaruhi PHBS dalam tatanan rumah tangga, diantaranya factor ekonomi, social budaya, tingkat pengetahuan, tingkaat pendidikan, adanya peranan tenaga kesehatan dan pengaruh dari tokoh masyarakat. (Dinkes, 2010)

Pengetahuan tentang PHBS sangat penting dikuasai oleh setiap individu didalam rumah tangga, terutama kepala keluarga. Pengetahuan kepala keluarga tentang PHBS sangat berpengaruh terhadap sikap dan prilaku setiap anggota keluarga menuju pola hidup bersih dan sehat dalam sehari-hari. Jika salah satu indicator PHBS dalam tatatnan rumah tangga tidak terlaksana, maka kategori PHBS dalam keluarga itu adalah buruk. Penyebab utama rendahnya PHBS dalam tatanan rumah tangga adalah adanya kebiasaan merokok kepala keluarga di dalam rumah. Adapun tugas tanggung jawab kepala keluarga adalah mencari nafkah, melindungi keluarga, mengambil keputusan, memelihara hubungan kekerabatan dan hubungan yang harmonis dengan istrinya (Razwanti, 2011).

Tingkat pendidikan akan mempengaruhi cara berfikir seseorang dalam berprilaku. Notoatmodjo, 2010 mengatakan bahwa suatu prilaku akan langgeng dengan adanya pendidikan yang dimiliki seseorang terssebut. Dengan pendidikan akan membantu seseorang berfikir dan menerapkan PHBS dengan baik. Penelitian pratama (2009) tentang hubungan PHBS di desa Mangunharjo Jawa Tengah, bahwa tingkat pendidikan berpengaruh terhadap motivasi kepala keluarga dan anggota keluarga dalam melaksanankan PHBS didalam keluarga. Rata-rata tingkat pendidikan penduduk di desa Mangunharjo 55,98\% hanya lulus SD, tidak tamat SD dan tidak sekolah. Dapat dikatakan tingkat pendidikan penduduk di desa Mangunharjo lebih dari setengah jumlah penduduknya berpendidikan rendah. 
Salah satu penyebab rendahnya perolehan tingkat keberhasilan program PHBS di desa Mangunharjo adalah kemauan ataupun motivasi masyarakatnya. Motivasi merupakan suatu usaha untuk meningkatkan kegiatan dalam mencapai suatu tujuan. Motivasi sangat dibutuhkan sebagai penggerak yang ada dalam diri individu untuk melakukan sesuatu. Motivasi intrinsik lebih utama dari pada motivasi ekstrinsik karena motivasi instrinsik timbul dari dalam diri individu sendiri tanpa adanya rangsangan dari luar. Motivasi instrinsik lebih murni dan langgeng serta tidak bergantung pada dorongan atau pengaruh orang lain (Pratama, 2010)

Peran tenaga kesehatan sebagai penggerak eksternal juga sangat besar dalam membantu terwujudnya PHBS dalam tatanan rumah tangga. Dengan pemberian edukasi dan penyuluhan tentang PHBS akan membantu masyarakat untuk memahami pola PHBS dalam kehidupan sehari-hari (Hasibuan, 2004). Peran tenaga kesehatan sangat berpengaruh terhadap pelaksanaan PHBS dalam lingkungan keluarga. Tenaga kesehatan adalah orang terdepan dalam memberikan pelayanan kesehatan dan memberikan edukasi tentang pentingnya pelaksaan PHBS di dalam rumah tangga. Pelayanan yang diberikan dapat dilakukan kunjungan rumah kerumah, atau pemnyuluhan di kantor desa saat ada acara keluarahan / desa, dapat menggunakan media bergambar dan leaflet tentang PHBS (Edi, 2010).

Tokoh masyarakat juga merupakan lini terdepan dalam memberikan contoh dan motivasi kepada masyarakat dalam melaksanakan PHBS dalam tatanan rumah tangga. Bentuk appresiasi yang dilakukan tokoh masyarakat seperti mendukung sosialisasi gerakan pelaksanaan PHBS dalam tatanan rumah tangga, memfasilitasi tenaga kesehatan dan masyarakat akan kebutuhan ruangan dan gedung kelurahan/ balai desa saat adanya penyuluhan PHBS, dll (Edi, 2010).

Penelitian Rai (2011) tentang peranan keluarga dalam melaksanakan PHBS di Sidoarjo adalah terdapatnya hubungan antara faktor motivasi keluarga melaksanakan PHBS sehubungan dengan adanya akses informasi dari tenaga kesehatan dan tokoh masyarakat yang ada di desa tersebut.

Berdasarkan hasil Riset Kesehatan Dasar (Riskesdas) 2013, secara nasional perbandingan pencapaian PHBS penduduk kota dan pedesaan yaitu, penduduk yang telah memenuhi kriteria PHBS baik sebesar 32,3\%. Pencapaian rumah tangga dengan PHBS baik lebih tinggi diperkotaan dengan persentase $41,5 \%$ dibanding dipedesaan dengan persentase 22,8\%, dari 10 indikator PHBS tatanan rumah tangga yang telah ditetapkan persentasenya adalah persalinan ditolong oleh tenaga kesehatan $(87,6 \%)$, menggunakan air bersih $(82,2 \%)$, menggunakan jamban sehat $(81,9 \%)$, tidak merokok didalam rumah $(78,8 \%)$, memberantas jentik dirumah sekali seminggu $(77,4 \%)$, menimbang bayi dan balita $(68,0 \%)$, melakukan aktivitas fisik setiap hari $(52,8 \%)$, mencuci tangan dengan air bersih dan sabun (47,2\%), memberi ASI eksklusif $(38,0 \%)$, makan buah dan sayur setiap hari (10,7\%) (Depkes RI, 2013).

Berdasarkan profil Dinas Kesehatan Provinsi Riau persentase PHBS dirumah tangga mengalami peningkatan. Pada tahun 2010 persentasenya adalah $44,2 \%$ dan meningkat pada tahun 2011 yaitu menjadi 49,5\% (Novita, 2014). Meskipun demikian pelaksanaan PHBS didaerah pedesaan tetap menjadi sebuah sorotan dan program yamng berkelanjutan bagi pemerintah dan dinas kesehatan kabupaten (Dinkes Jogja, 2013). Hal ini diduga dipicu oleh tingkat kesadaran masyarakat yang hidup dikota dengan didesa dalam melakukan PHBS sangat berbeda karena perbedaan faktor status sosial, pendidikan, pengetahuan dan motivasi masyarakat (Edi, 2010).

Pada studi pendahuluan terhadap $12 \mathrm{KK}$ di RT 04/RW 02 desa kualu, diperoleh data bahwa masih terdapat $10 \mathrm{KK}$ yang kepala keluarganya merokok. Pembuangan sampah keluarga mayoritas dibakar. Tidak ada yang melakukan olaharaga teratur. Semuanya rumah tipe 36, dan $5 \mathrm{KK}$ diantaranya mempunyai anak $>5$ orang atau anggota keluarga yang tinggal tidak sesuai dengan besarnya rumah. 
Berdasarkan hal-hal tersebut di atas, maka peneliti tertarik untuk mengetahui faktorfaktor apa saja yang berhubungan dengan prilaku hidup bersih sehat (PHBS) di desa Kualu tahun 2016.

Tujuan Penelitian ini Untuk mengetahui apa sajakah faktor-faktor yang berhubungan dengan prilaku hidup bersih sehat (PHBS) di desa Kualu tahun 2016.

\section{METODE PENELITIAN}

Jenis penelitian adalah kuantitatif dengan desain penelitian korelasi dimana tujuannya hanya ingin mengetahui faktor-faktor yang berhubungan dengan prilaku hidup bersih sehat (PHBS) di tatanan rumah tangga desa Kualu tahun 2016

Penelitian dilakukan di desa kualu tahun 2016. Penelitian dilakukan mulai bulan Oktober 2016 - Mei tahun 2016. Populasi dalam penelitian ini adalah seluruh kepala keluarga yaitu berjumlah 350 kepala keluarga didesa kualu.

Pada penelitian ini peneliti mengambil sampel dengan cara metode pengambilan sampel dalam bentuk random. Teknik pengambilan sampel menggunakan metode Probability sampling yaitu pengambilan sampel dengan modifikasi dari sampling sitematis (Sugiyono, 2010).

Analisa data adalah menguraikan atau memecahkan suatu keseluruhan menjadi bagian-bagian atau komponen - komponen yang lebih kecil agar dapat mengetahui komponen yang menonjol, membandingkan antara komponen yang satu dengan komponen yang lainnya (menggunakan angka selisih atau angka rasio), membandingkan salah satu atau beberapa komponen dengan keseluruhan (persentase) ( Hasan, 2006 ). Analisis data dilakukan secara univariat terhadap variabel dan sub variabel dengan menghitung distribusi Tabel 1 dan proporsinya. Dengan bantuan SPSS. Analisis bivariate menggunakan Chi Square.

\section{HASIL DAN PEMBAHASAN}

Dari tabel 1 menunjukkan bahwa mayoritas pengetahuan kepala keluarga tentang Perilaku Hidup Bersih dan Sehat di Rumah Tangga dalam kategori pengetahuan baik sebanyak $64 \%$, pendidikan menengah SMA sebanyak $59 \%$, Peranan Tenaga Kesehatan dalam Perilaku Hidup Bersih dan Sehat pada Rumah Tangga di Desa kualu adalah kurang berperan, sebanyak $54 \%$. Peranan Tokoh Masyarakat tentang Perilaku Hidup Bersih dan Sehat pada Rumah Tangga di Desa Kualu adalah baik (ada berperan) sebanyak $54 \%$. Dan pelaksanaan PHBS adalah Tidak Ber-PHBS sebanyak 51\%.

\section{Pengetahuan}

Hasil penelitian menggambarkan bahwa mayoritas pengetahuan kepala keluarga di Desa kualu tahun 2016 tentang PHBS dirumah tangga adalah baik sebanyak $64 \%$. Pertanyaan pengetahuan tentang PHBS mengacu kepada 10 indikator PHBS. Pada penelitian ini mayoritas responden mampu menjawab dengan baik dan memahami tentang indikator PHBS dalam kehidupan sehari-hari.

Hal diatas menggambarkan mayoritas kepala keluarga sudah memahami tentang PHBS dirumah tangga. Jika dihubungkan dengan pendidikan kepala keluarga yaitu mayoritas kepala keluarga di Desa Kualu pendidikannya tingkat menengah sebanyak $59 \%$, yang dapat mempengaruhi pengetahuan kepala keluarga tentang PHBS dirumah tangga, hal ini sesuai dengan teori yang mengatakan bahwa semakin tinggi tingkat pendidikan seseorang maka semakin tinggi pula tingkat pengetahuannya (Notoatmodjo, 2007).

\begin{tabular}{ccccc}
\hline \multirow{2}{*}{ No } & & Variable & Jumlah & Persentase \\
\hline \multirow{2}{*}{1} & Pengetahuan & & \\
& $1 . \quad$ Kurang & 36 & 36 \\
& $2 . \quad$ Baik & 64 & 64 \\
\hline \multirow{2}{*}{2} & Pendidikan & 26 & 26 \\
& $1 . \quad$ Rendah & 59 & 59 \\
\hline
\end{tabular}




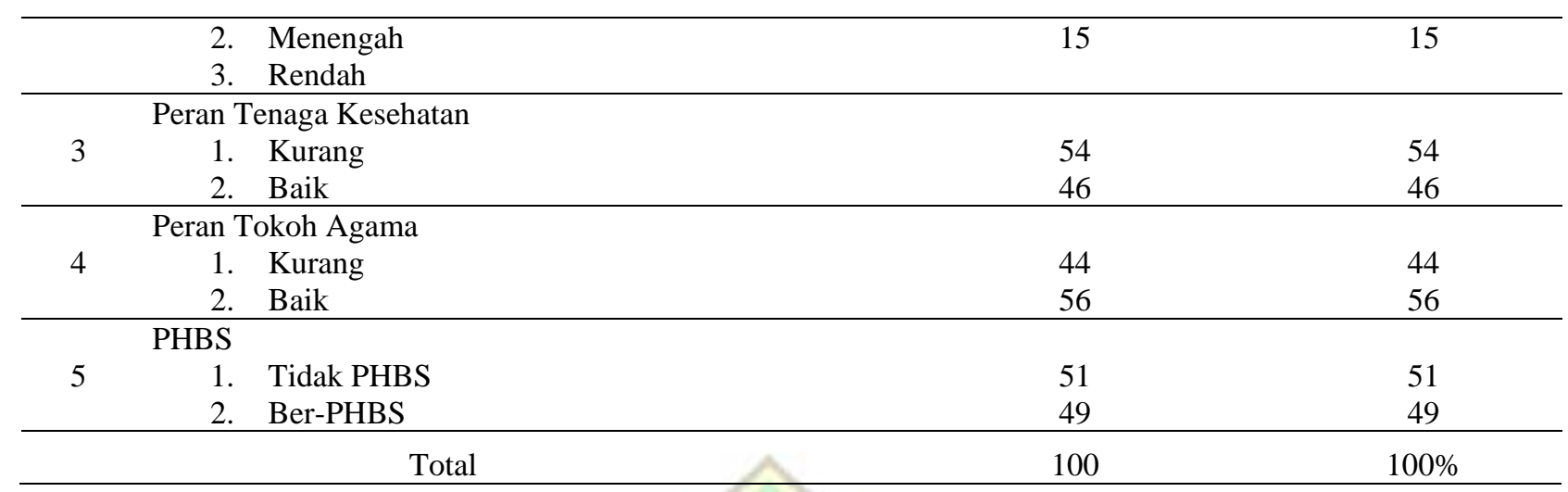

Table 2 Bivariat

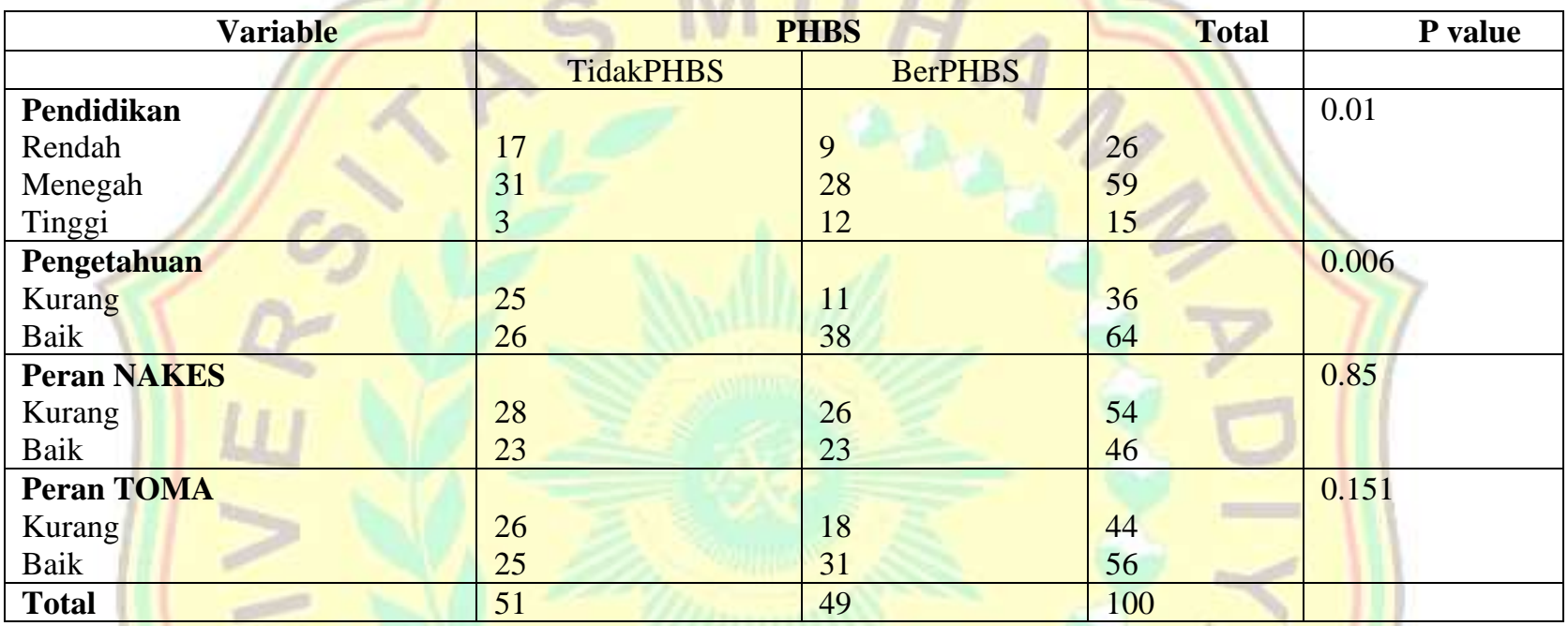

Hal ini juga sama dengan penelitian Hernita (2010) diperoleh pendidikan responden (kepala keluarga) sebagian besar pendidikan menengah jumlah 59 kepala keluarga (59 \%), hal ini berkaitan dengan pengetahuan seseorang karena pendidikan merupakan hal dasar yang dapat membentuk pola pikir seseorang sehingga mempengaruhi pengetahuan dan sikap seseorang dalam kehidupan sehari - hari.

Pengetahuan Kepala keluarga baik juga dipengaruhi oleh umur, mayoritas berumur 2535 tahun sebanyak 38 orang (38\%). Masa ini merupakan dewasa menengah, merupakan waktu untuk membentuk kemandirian pribadi dan ekonomi dan merupakan masa meningkatnya minat nilai - nilai pada generasi berikutnya, semakin bertambah umur semakin semakin bertambah pula pengetahuan yang didapat (Santrock, 2007).
Selain faktor diatas sumber informasi juga mempengaruhi pengetahuan kepala keluarga. Menurut peneliti hal ini dapat dipengaruhi oleh adanya akses informasi yang didapatkan oleh responden dari berbagai hal seperti dari tenaga kesehatan, buku bacaan, televisi, radio serta kemudahan dalam akses Internet dari mobile phone (gadget) yang mereka miliki. Jadi kepala keluarga akan lebih memahami tentang segala yang didapatnya dan lebih aktif untuk mencurahkan pengalaman yang didapat karena pengalaman dapat mempengaruhi sikap dan perilaku seseorang (Notoatmodjo, 2007).

\section{Pendidikan}

Hasil penelitian menggambarkan bahwa mayoritas pendidikan kepala keluarga di Desa kualu tahun 2016 tentang PHBS dirumah tangga adalah tingkat menengah sebanyak 59 orang (59\%). 
Pendidikan adalah bimbingan yang diberikan seseorang pada orang lain terhadap sesuatu hal agar mereka dapat memahami. Tidak dapat dipungkiri bahwa makin tinggi pendidikan seseorang semakin mudah pula mereka menerima informasi, dan pada akhirnya makin banyak pula pengetahuan yang dimilikinya. Terdapat hubungan yang kuat antara tingkat pendidikan individu dengan sikap dan prilakunya dalam mememlihara kesehatan (Notoatmodjo, 2007).

Hasil penelitian Agung 2010 di Jombang, terdapat hubungan antara tingkat pendidikan responden dengan prilaku hidup bersih sehat. Semakin rendah pendidikannya maka prilakunya kurang baik dalam PHBS dan semakin tinggi pendidikannya semakin baik prilakunya dalam melaksanakan PHBS dalam tatanan rumah tangganya sehari-hari.

\section{Peranan tenaga kesehatan}

Hasil penelitian menggambarkan bahwa mayoritas peranan Tenaga Kesehatan dalam PHBS di Desa kualu tahun 2016 adalah kurang baik (kurang berperan) sebanyak $54 \%$.

Perilaku seseorang atau masyarakat ditentukan oleh pengetahuan, sikap, kepercayaan, tradisi, dan sebagainya dari orang atau masyarakat yang bersangkutan. Selain itu, ketersediaan fasilitas, sikap dan perilaku petugas kesehatan terhadap kesehatan akan mendukung dan memperkuat terbentuknya perilaku. (jurnal Kesmas, 2014)

Pada penelitian ini peranan tenaga kesehatan tampak tidak begitu menonjol dalam memotivasi dan menggalakkan PHBS secara konkrit di tengah masyarakat, berdasarkan wawancara peneliti setelah menerima hasil kuesioner dari responden disampaikan bahwa tenaga kesehatan hanya memberikan sugesti, saran dan pendapat tentang PHBS saat masyarakat berkunjung untuk berobat ke puskesmas pembantu, ke klinik atau ke praktek bidan mandiri yang ada dilingkungan sekitar desa Kualu, namun tenaga kesehatan jarang turun kelapangan untuk memberikan penyuluhan PHBS, kecuali hanya turun untuk posyandu atau kegiatan bakti sosial yang mereka adakan.
Menurut peneliti kurang berperannya tenaga kesehatan dalam memberikan penyuluhan tentang PHBS ini di Desa kualu karena kurangnya koordinasi dan kerjasama antar petugas Pustu dengan bidan praktek mandiri dalam menggalakkan dan menyuluh tentang PHBS di masyarakat, dengan luasnya wilayah kerja pustu desa kualu dengan 3 orang tenaga kesehatan yang tersedia, maka menyebabkan petugas tidak punya banyak waktu dalam melaksanakan penyuluhan PHBS di masyarakat, dan mereka limpahkan dan kerjasama dengan tokoh masyarakat setempat untuk menjalankan program PHBS sebagai perpanjangan tangan mereka. Dan adanya asumsi bahwa di Desa kualu masyarakatnya secara demografi sudah cukup maju dan terdapat banyak perumahan nasional yang sudah dibangun sesuai standar kesehatan, yang dihuni oleh para pendatang dengan berbagai latar belakang.

Peran tenaga kesehatan yang kurang dalam penyuluhan PHBS, ternyata diperkuat dengan data penelitian menunjukkan bahwa tingkat PHBS masyarakat di Desa Kualu tergolong kurang baik, dimana 54 responden $(53 \%)$ dari 100 responden memiliki prilaku PHBS yang kurang baik. Artinya masih rendah tingkat kesadaran masyarakat desa kualu tentang pentingnya perilaku hidup sehat dalam kehidupan rumah tanggga mereka, dan perlu arahan dari tenaga kesehatan meskipun sumber informasi bisa mereka dapatkan dari sumber lainnya. Untuk itu agar semua masyarakat desa Kualu meningkatkan dan mempertahankan PHBS yang baik dalam tatanan rumah tangga mereka dalam sehari-hari.

\section{Peranan Tokoh masyarakat}

Hasil penelitian menggambarkan bahwa mayoritas peranan Tokoh Masyarakat dalam PHBS di Desa kualu tahun 2016 adalah baik (berperan) sebanyak $56 \%$.

Menurut Judge dan Bono (2001) dalam jurnal Kesmas 2014, teori perubahan perilaku self efficacy yang menekankan adanya contoh dalam diri seseorang sehingga perilaku seseorang dicontoh oleh masyarakat sekitar hingga menjadikan sebuah budaya masyarakat. Teori perubahan perilaku ini biasa digunakan 
dalam perubahan perilaku masyarakat khususnya kesehatan dengan memanfaatkan tokoh masyarakat sekitar yang dianggap mempunyai peran penting dan mempunyai suritauladan khususnya dibidang kesehatan. Pendekatan perubahan perilaku masyarakat didasarkan pada tokoh masyarakat sekitar yang mempunyai pengaruh lebih atau suritauladan dalam perilaku hidup sehat.

Penelitian Dedek Mulyanti, 2009 didapatkan hasil bahwa ada hubungan antara factor reinforcing (penguat) dari tokoh masyarakat terhadap prilaku PHBS di masayarakat. Factor reinforcing dari tokoh masyarakat merupakan factor eksternal diluar responden dalam menentukan sikap dan prilaku nya dalam menjaga kesehatannya.

Pada penelitian ini peneliti dapat mendeskripsikan bahwa peranan tokoh masyarakat tampak sangat baik dalam kehidupan sehari-hari, karna tokoh masyarakat tersebut berada ditengah lingkungan tempat tinggal masyarakat (responden), sehingga tokoh masyarakat dapat secara langsung mencontohkan dan memotivasi mereka untuk ber-PHBS dalam kehidupan sehari-hari, seperti anjuran dan program rutin untuk gotong royong membersihkan lingkungan, mengumumkan kegiatan posyandu dan pemilihan tempat pelayanan kesehatan untuk ibu dan anak. Hal ini peneliti dapatkan dari wawancara dengan responden setelah menerima hasil kuesioner penelitian. Meskipun demikian hal ini juga tentunya dipengaruhi juga oleh kesadaran masyarakat dalam menerima masukan dari tokoh masyarakat yang ada dilingkungan mereka.

\section{KESIMPULAN SARAN}

Berdasarkan hasil penelitian dan pembahasan, maka penulis mengambil kesimpulan: Terdapat hubungan antara factor pengetahun, dan pendidikan dengan PHBS

Diharapkan bagi Puskesmas Pembantu dan sektor Kesehatan lainnnya dapat mempertahankan dan selalu memberi informasi kepada masyarakat tentang PHBS dirumah tangga untuk lebih meningkatkan pengetahuan kepala keluarga. Dengan harapan kepala keluarga dapat menerapkan atau menciptakan PHBS dirumah tangga.

\section{DAFTAR PUSTAKA}

Chandra, Budiman. 2006. Pengantar Kesehatan Lingkungan, Jakarta : PT EGC

Depkes RI. 2006. Pedoman Umum Gizi Seimbang, Jakarta

Depkes RI, 2013. Riset Kesehatan Dasar (Riskesdas) 2013

http://depkes.go.id/downloads/riskesda s2013/Hasil\%20Riskesdas\%202013.pd f\#page $=12 \&$ zoom $=$ auto, 0,644 , diperoleh tanggal 26 Februari 2014

Depkes RI,2013. Kamus Depkes tentang Kepala keluarga. http://www.depkes.go.id/index.php?vw $=2 \& p g=$ Kamus, diperoleh tanggal 26 Februari 2014

Hasni, Hidayatul. 2012. Hubungan pengetahuan dan tingkat pendidikan kepala keluarga terhadap perilaku hidup bersih dan sehat keluarga. http://repository.unand.ac.id/17815/1/PE NELITIAN1\%20HIDAYATUL\%20HAS NI.pdf, diperoleh tanggal 26 Februari 2014

Hasan, Iqbal. 2006. Analisis Data Penelitian dengan Statistik, Jakarta : PT Bumi Aksari

Machfoedz, Ircham. 2008. Menjaga Kebersihan Rumah dari Berbagai Penyakit, Yogyakarta : PT Fitramaya

Maryunani, Anik. 2013. Perilaku Hidup Bersih dan Sehat, Jakarta : PT Trans Info Media

Notoatmodjo, Soekidjo. 2003. Ilmu Kesehatan Masyarakat, Jakarta : PT Rineka Cipta

Notoatmodjo, Soekidjo. 2005. Metodologi Penelitian Kesehatan, Jakarta : PT Rineka Cipta

Notoatmodjo, Soekidjo. 2007. Promosi Kesehatan dan Ilmu Perilaku, Jakarta : PT Rineka Cipta 
Notoatmodjo, Soekidjo. 2010. Promosi Kesehatan Teori dan Aplikasi, Jakarta : PT Rineka Cipta

Puswati, Desti. dkk, 2013. Panduan Penyusunan dan Penulisan Karya Tulis Ilmiah, Pekanbaru :Stikes Payung Negeri

Razwanti, Sri. 2004. Pemberian Bekal Pengetahuan Terhadap Peran Kepala Keluarga.http://lontar.ui.ac.id/opac/the mes/libri2/detail.jsp?id=20286874\&lok asi=lokal, diperoleh tanggal 20 Februari 2014

Riduwan. 2009. Rumus dan Data dalam Aplikasi Statistika, Bandung : PT Alfabeta

Santrock, Jhon. 2007. Remaja, Jakarta : PT Erlangga

Sugiyono. 2005. Statistika untuk Penelitian, Bandung : PT Alfabeta

Taufik, muhamad. 2013. perilaku Hidup Bersih dan Sehat. 